\title{
Wounds: an overlooked burden (Part 1) - effective wound management starts with proper wound assessment
}

\author{
H Parkar, (iD AD Cromarty \\ Department of Pharmacology, Faculty of Health Sciences, University of Pretoria, South Africa \\ Corresponding author, email: hafiza.parkar@up.ac.za
}

Healthcare professionals in general practice are tasked with treatment and management of wounds on a daily basis. The prognoses of these wounds are directly affected by the ability of the clinician to assess these wounds according to several parameters, including the wound type and the features which determine whether a wound is acute or transforming to a chronic wound. This can be achieved by proper and continuous wound assessment, which should guide wound treatment strategies to ensure optimal wound healing and prevent progression to complicated wounds.

Keywords: wound assessment, wound aetiology, acute wound, chronic wound, primary intention wounds, secondary intention wounds

\section{Introduction}

Increasing age and compromised immunity are two factors prevalent in South African patients, which will result in an increase in the incidence and prevalence of wounds requiring appropriate wound management and care. This is due to the high incidence of comorbidities such as obesity, diabetes, cardiac diseases, HIV infections and neuropathies, all of which have a direct or indirect impact on the healing time of wounds. ${ }^{1}$

In South Africa, where a referral to a wound care specialist is not always possible due to time and cost constraints, it often falls on primary health caregivers to treat and manage wounds. These wounds range from uncomplicated acute wounds sustained during an injury, to chronic wounds with complications arising from patient pathologies and aggravated by comorbidities or being bedridden. Management and effective treatment, especially of chronic wounds, is crucial to prevent poor prognoses or further deterioration of the wound that in extreme cases could result in amputations.

A proper understanding of wound aetiology and the ability to assess the status of different wounds will guide the most effective wound treatment. This article highlights wound types and classifications as well as briefly discussing the considerations to be made prior to wound therapy.

\section{Assessing wounds}

The most common wounds occur from a traumatic injury to the skin, although many wounds can also result from internal causes mostly associated with poor blood supply to an area of skin. Human skin is a complex multi-layered organ with many functions including sensation, thermal control and serving as a tough protective layer. ${ }^{2}$ Broadly speaking a wound is a breach in the integrity of the skin, resulting in a breakdown of its protective functions. ${ }^{3}$ Different types of wounds present in different ways and are summarised in Table I.
Table I: Classification of acute wounds based on their causes ${ }^{3-6}$

\begin{tabular}{ll}
\hline Aetiology & Type of wound \\
\hline Surgery (sterile) & $\begin{array}{l}\text { Clean sterile surgical incisional } \\
\text { and excisional wounds }\end{array}$ \\
\hline Mechanical injury & $\begin{array}{l}\text { Abrasions, avulsions, punctures, } \\
\text { lacerations, bites, contusions or } \\
\text { haematomas }\end{array}$ \\
\hline Burn wounds & $\begin{array}{l}\text { First, second, third and fourth } \\
\text { degree burn wounds caused by } \\
\text { extreme heat, extreme cold or } \\
\text { chemical exposure }\end{array}$ \\
\hline $\begin{array}{l}\text { Continuous pressure, } \\
\text { ischaemia resulting from } \\
\text { disease or neuropathies }\end{array}$ & $\begin{array}{l}\text { Pressure ulcers (bed sores), lower } \\
\text { leg ulcers, diabetic foot ulcers } \\
\text { (DFU), aphthous ulcers, peptic } \\
\text { ulcers, carcinomas }\end{array}$ \\
\hline
\end{tabular}

\section{Wound healing classification}

The manner in which wounds heal can be broadly classified as either primary or secondary intention, based on the extent of tissue loss at the time of injury. Wounds where the opposing wound edges can be approximated and stabilised in place are defined as healing by primary intention, and require that minimal tissue loss has occurred with limited disruption in the continuity of the supporting basement membrane of the skin. These wounds exhibit limited loss of epithelial cells and connective tissue. An example of healing by primary intention is the healing of a clean uninfected surgical incision or an excision wound that is closed by sutures. ${ }^{4,5}$

Healing by secondary intention refers to the healing process where extensive tissue loss has occurred such as full skinthickness wounds. The repair process in this instance is more complicated as compared to primary intention healing due to the requirement for tissue replacement from the wound bed through formation of granulation tissue. ${ }^{4,5}$ Healing by secondary 
intention requires extended healing time, leaving wounds vulnerable to external, pathophysiological and metabolic factors such as infection, oedema, hypoxia, ischaemia, necrosis, putrification, excessive drying and poor blood supply, all of which can slow down the wound healing process. ${ }^{4,5}$

Wounds may be further classified as acute or chronic wounds based on the time the wound takes to reach healing milestones. ${ }^{7}$ Acute wounds proceed through the highly ordered sequential but overlapping wound healing phases in an orderly manner, and within a predictable time frame (4-6 weeks), resulting in almost complete restoration of the anatomical and functional integrity of the wounded area. ${ }^{8,9}$ Acute wounds usually heal in a timeous and predictable fashion, but this can be hindered by numerous external or intrinsic factors such as infection, debris or patient pathologies, resulting in an extended delay in complete healing or progression to a non-healing or "chronic wound".

Chronic wounds are those wounds that do not progress through the sequential and overlapping wound healing phases in the expected manner, and do not heal within an expected time frame (unhealed after 6 weeks). These wounds generally appear to be retained in a pathological state of inflammation with continuous tissue destruction in the wound bed or edges. These wounds either recur after partial healing or require extended time and debriding treatments to heal. ${ }^{8,9}$ The common causes of chronic wounds are local infection, hypoxia, trauma, presence of foreign (solid or otherwise) material in the wound area as well as pathologies such as diabetes, malnutrition, immunodeficiency or medication. ${ }^{8,9}$

While a healthy acute wound can take as little as two weeks to heal completely, the healing process may become impeded, in which case the wound may progress into a chronic wound that can take six months or more to heal completely, if at all. Patients with chronic wounds require longer periods of care, often with intensive or specialist treatments and extended or repeated hospital visits with an ever-increasing risk of developing complications over time. , $^{89}$

The ability to distinguish an acute wound from an early stage chronic wound is an important skill. There are numerous factors that can help a clinician to differentiate these from each other during an assessment of the wound. These include but are not limited to the time taken to heal, the physical appearance of the wound bed and wound edges, the amount of exudate, the appearance of the granulation and surrounding tissue as well as the presence of infection. These factors are summarised in Table II.

Chronic wounds are estimated to have a negative impact on patient quality of life comparable to that of chronic diseases. ${ }^{12}$ Wound care should therefore be initiated as early as possible with the aim of effectively promoting healing and preventing the formation of chronic wounds, which negatively impact patient health and emotions, medical care costs and overall demand on the healthcare systems.

It is recommended that patients with complicated wounds be referred to dedicated wound care clinics where trained specialists will monitor, manage, and treat the wound till it is completely healed. These wound clinics use proactive wound healing strategies to lighten the burden on primary healthcare physicians, patients, their families and healthcare systems.

\section{Factors to consider prior to wound therapy}

Different wounds require a targeted treatment approach depending on the wound age, aetiology, extent of damage and the wound location. These parameters should be evaluated during proper and continuous wound assessment. The main goals of wound therapy are to encourage wound closure and to re-establish function of the wounded area in a reasonable time. This is achieved by keeping the wound moist, which would support growth of granulation tissue and angiogenesis, but not

Table II: Summary of factors differentiating between acute and chronic wounds ${ }^{10,11}$

\begin{tabular}{|c|c|c|}
\hline Distinguishing factor & Acute wound & Chronic wound \\
\hline Time to heal & 4-6 weeks & $>6$ weeks \\
\hline Wound bed & $\begin{array}{l}\text { Granulation tissue appears soft and pink } \\
\text { Epithelialising tissue is pink to almost white, } \\
\text { and overlies healthy granulation tissue }\end{array}$ & $\begin{array}{l}\text { Granulation tissue appears dark red } \\
\text { May have excessive granulation tissue due to infection } \\
\text { May show signs of necrosis (hard, dry and black) }\end{array}$ \\
\hline Wound edges & $\begin{array}{l}\text { Colour: pink edges indicate healing } \\
\text { Evidence of wound contraction: wound } \\
\text { edges indicate healing }\end{array}$ & $\begin{array}{l}\text { Colour: brownish edges indicate hypoxia and erythema indicates } \\
\text { infection } \\
\text { Raised edges may indicate hyper granulation tissue } \\
\text { Rolled edges can inhibit healing } \\
\text { Increased pain sensation or complete numbness } \\
\text { Requires regular debriding }\end{array}$ \\
\hline Exudate & $\begin{array}{l}\text { Moderate amount of exudate that keeps the } \\
\text { wound sufficiently moist }\end{array}$ & $\begin{array}{l}\text { May produce excessive amounts of exudate leading to tissue } \\
\text { maceration } \\
\text { Limited exudate produced leading to the wound bed and edges } \\
\text { drying out } \\
\text { Exudate may be viscous and odorous when infection is present }\end{array}$ \\
\hline Surrounding tissue & $\begin{array}{l}\text { Appears healthy and unaffected } \\
\text { Slight oedema }\end{array}$ & $\begin{array}{l}\text { May show signs of cellulitis or maceration } \\
\text { Oedema, red and "angry" }\end{array}$ \\
\hline Infection & Seldom show signs of infection & $\begin{array}{l}\text { May experience heat, redness, swelling, and pain } \\
\text { May show increased exudate, delayed healing, bleeding on contact, } \\
\text { odour } \\
\text { Abnormal granulation tissue }\end{array}$ \\
\hline
\end{tabular}


wet which can cause tissue maceration. The dressings must keep wounds clean and sterile. A wound bed and edges that show signs of dead or dying tissue should be debrided. Dressings of various types can be used to control exudate and to prevent further wounding. ${ }^{13}$

Generally, acute wounds of primary intention are easily treated with numerous potential options, and if they are not infected and are without patient comorbidities, will heal easily and rapidly without any further specialist care. ${ }^{14}$ In contrast, the initial selection of a wound treatment regimen for an existing chronic wound can be quite complex, as this decision impacts on the prognosis of the wound and can determine the length of wound treatment and the patient's quality of life. It should be stated that no single treatment or treatment combination will be the correct choice for all wounds. ${ }^{13}$

Current wound therapies are aimed at restoring the protective function of the skin while supressing microbial infections and excessive immune-related damage at the wound site. Where appropriate, the edges of the wound are brought together to eliminate tissue gaps using different treatment strategies..$^{13,15}$ On the other hand, emerging therapies are centred around the stimulation of appropriate natural wound healing processes rather than targeting factors that hinder the healing process. These therapies either stimulate specific phases of the wound healing process or supplement cellular and molecular functions. ${ }^{16,17}$ The next article in this series will expand on current and emerging wound therapies.

\section{In summary}

Time since the wounding took place determines the way in which a wound should be treated, as does the determination of the wound type and the classification of the healing process that will be followed. Proper wound assessment will ensure that the best treatment options are followed, whether this entails initial wound preparation like debriding to reduce the risk of progression to a chronic wound or performing simple wound closure with a dressing. Proper assessment should guide the use of the most effective treatments or dressings, which accommodate the patient's situation yet are practical, affordable and prevent the progression into complicated wounds.

\section{Conflict of interest}

The authors declare no conflict of interest.

\section{Funding source}

No funding source to be declared.

\section{ORCID}

H Parkar (iD https://orcid.org./0000-0003-3732-1409 D Cromarty (iD) https://orcid.org./0000-0002-9512-6081

\section{References}

1. Vowden P, Vowden K. The economic impact of hard-to-heal wounds: promoting practice change to address passivity in wound management. Wounds International. 2016;7(2):10-5.

2. Archer CB. Functions of the skin. Rook's Textbook of Dermatology. 2010;1:1-11. https://doi.org/10.1002/9781444317633.ch4.

3. Leaper DJ, Harding KG. Wounds: biology and management: Oxford University Press, USA; 1998.

4. Velnar T, Bailey T, Smrkolj V. The wound healing process: an overview of the cellular and molecular mechanisms. Journal of International Medical Research. 2009;37(5):1528-42. https://doi.org/10.1177/147323000903700531.

5. Rivera $A E$, Spencer JM. Clinical aspects of full-thickness wound healing Clinics in Dermatology. 2007;25(1):39-48. https://doi.org/10.1016/j. clindermatol.2006.10.001.

6. Leaper DJ. $A B C$ of wound healing: traumatic and surgical wounds. British Medical Journal. 2006;332(7540):532-5. https://doi.org/10.1136/ bmj.332.7540.532.

7. Mallefet $P$, Dweck $A$. Mechanisms involved in wound healing. Biomedical Scientist. 2008;52(7):609.

8. Guo S, Dipietro LA. Factors affecting wound healing. Journal of Dental Research. 2010;89(3):219-29. https://doi.org/10.1177/0022034509359125.

9. Demidova-Rice TN, Hamblin MR, Herman IM. Acute and impaired wound healing: pathophysiology and current methods for drug delivery, part 1: normal and chronic wounds: biology, causes, and approaches to care. Advances in Skin and Wound Care. 2012;25(7):304-14. https://doi.org/10.1097/01. ASW.0000416006.55218.d0.

10. Grey JE, Enoch S, Harding KG. ABC of wound healing: wound assessment. British Medical Journal (Clinical research ed). 2006;332(7536):285-8. https://doi. org/10.1136/bmj.332.7536.285.

11. Healy B, Freedman $A . A B C$ of wound healing: infections. British Medical Journal. 2006;332(7545):838-41. https://doi.org/10.1136/bmj.332.7545.838.

12. Hurd T. Understanding the financial benefits of optimising wellbeing in patients living with a wound. Wounds International. 2013;4(2):13-7.

13. Dabiri G, Damstetter E, Phillips T. Choosing a wound dressing based on common wound characteristics. Advances in Wound Care. 2016;5(1):32-41. https://doi. org/10.1089/wound.2014.0586.

14. Frykberg RG, Banks J. Challenges in the treatment of chronic wounds. Advances in Wound Care. 2015;4(9):560-82. https://doi.org/10.1089/wound.2015.0635.

15. Enoch S, Grey JE, Harding KG. ABC of wound healing: non-surgical and drug treatments. British Medical Journal. 2006;332(7546):900. https://doi. org/10.1136/bmj.332.7546.900.

16. Enoch S, Grey JE, Harding KG. ABC of wound healing: recent advances and emerging treatments. BMJ: British Medical Journal. 2006;332(7547):962. https:// doi.org/10.1136/bmj.332.7547.962.

17. Vig K, Chaudhari A, Tripathi S, et al. Advances in skin regeneration using tissue engineering. International Journal of Molecular Sciences. 2017;18(4):789. https://doi.org/10.3390/ijms18040789. 